\title{
The importance of forecasting regional wind power ramping: a case study for the UK
}

Article

Accepted Version

Creative Commons: Attribution-Noncommercial-No Derivative Works 4.0

Drew, D. R., Cannon, D. J., Barlow, J. F., Coker, P. J. and Frame, T. (2017) The importance of forecasting regional wind power ramping: a case study for the UK. Renewable Energy, 114. pp. 1201-1208. ISSN 0960-1481 doi:

https://doi.org/10.1016/j.renene.2017.07.069 Available at https://centaur.reading.ac.uk/71460/

It is advisable to refer to the publisher's version if you intend to cite from the work. See Guidance on citing.

To link to this article DOI: http://dx.doi.org/10.1016/j.renene.2017.07.069

Publisher: Elsevier

All outputs in CentAUR are protected by Intellectual Property Rights law, including copyright law. Copyright and IPR is retained by the creators or other copyright holders. Terms and conditions for use of this material are defined in the End User Agreement.

www.reading.ac.uk/centaur 
Central Archive at the University of Reading

Reading's research outputs online 


\title{
1 The importance of forecasting regional wind power ramping: A 2 case study for the UK
}

\author{
3 Daniel. R. Drew ${ }^{1, *}$, Dirk. J. Cannon ${ }^{1,}$, Janet. F. Barlow ${ }^{1}$, Phil. J. Coker ${ }^{2}$ and Tom. Frame ${ }^{1}$
}

$4 \quad 1$ Department of Meteorology, University of Reading, Reading, UK

52 School of Construction Management and Engineering, University of Reading, Reading, UK

$6 *$ Author to whom correspondence should be addressed; E-Mail: d.r.drew@ reading.ac.uk;

7 Tel.: +44 (0)118378 7696

8 Abstract

9 In recent years there has been a significant change in the distribution of wind farms in Great Britain,

10 with a trend towards very large offshore farms clustered together in zones. However, there are

11 concerns these clusters could produce large ramping events on time scales of less than 6 hours as local

12 meteorological phenomena simultaneously impact the production of several farms. This paper

13 presents generation data from the wind farms in the Thames Estuary (the largest cluster in the world)

14 for 2014 and quantifies the high frequency power ramps. Based on a case study of a ramping event

15 which occurred on 3rd November 2014, we show that due to the large capacity of the cluster, a

16 localised ramp can have a significant impact on the cost of balancing the power system on a national

17 level if it is not captured by the forecast of the system operator. The planned construction of larger

18 offshore wind zones will exacerbate this problem. Consequently, there is a need for accurate regional

19 wind power forecasts to minimise the costs of managing the system. This study shows that state-of-

20 the-art high resolution forecast models have capacity to provide valuable information to mitigate this 21 impact.

Keywords: Wind; energy; ramping; predictability; offshore

\subsection{Introduction}

In recent years there has been a significant growth in wind power in the UK. Between 2008 and 2014, the installed capacity of wind turbines increased from $2.9 \mathrm{GW}$ to $12.4 \mathrm{GW}$ and the proportion of electricity provided by wind power increased from $1.5 \%$ to $9.3 \%$ [1]. Much of this growth is the result of the development of offshore wind. Following the construction of the offshore wind farms in the second round of developments (started by the Crown Estate in 2003); the offshore capacity has risen to approximately $5 \mathrm{GW}$ (40\% of total wind capacity). Much of this new capacity has been installed in a small number of very large wind farms which are located in clusters. For example, in the Thames Estuary alone there is approximately $1.7 \mathrm{GW}$ of capacity [2]. This trend looks set to continue as the third round of offshore wind development in the UK, launched in 2009, identified 9 zones within which a number of individual wind farms could be located. Consequently, following the construction of the round 3 wind farms the majority of GB wind capacity would be located offshore in clusters of very large wind farms $[3,4]$.

Concentrating large amounts of capacity in a small number of wind farms in close proximity can lead to large regional ramps in generation on time scales of minutes to hours as the impact of local meteorological phenomena could simultaneously impact production in several sites. Drew et al [5] showed that on time scales of less than 6 hours, the ramps in generation of the cluster of wind farms in the Thames Estuary were larger than those of the more spatially dispersed onshore wind farms. Large fluctuations in power on short time scales have also been observed at the Horns Rev wind farm [6, 7]. 
Given the large capacity of the offshore wind farms, these fluctuations could present a challenge to National Grid, the system operator responsible for ensuring a balance between supply and demand of electricity, particularly if they are not accurately forecasted. Making reliable forecasts of exactly where and when local ramping events will occur is a significant challenge. Potter et al. [8] identified three types of errors; phase error, magnitude error and location error. A phase error is defined as a ramping event which has the magnitude accurately predicted but occurs at the wrong time. A magnitude error is defined as a ramping event that is forecasted to occur at the correct time but with the wrong magnitude. A location error is defined as an error in the geographical location of the meteorological feature which produces the ramping event. The predictability of ramping events has been investigated using a range of methods. At relatively short lead times (minutes to hours), forecasts can be made using simple statistical methods such as ARMA (auto-regressive moving average) [9] or more complicated data-driven methods such as artificial neural networks (ANN) [10,11]. Forecasts for the next few hours up to several days ahead rely on numerical weather prediction (NWP) models [12, 13, 14]. NWP model forecasts are initialised from analyses, which represent the observed state of the atmosphere on a three-dimensional grid by blending observational data with an earlier forecast. A forecast of the future state of the atmosphere is then made by mathematically modelling the dynamics and other physical processes. Due to its chaotic nature, the state of the atmosphere at a future time is sensitive to small errors at the start of the forecast. Consequently, there is uncertainty in NWP model forecasts, which grows with increasing lead time. To determine this uncertainty the NWP model can be run a number of different times from slightly different starting conditions (designed to represent the uncertainty in the initial state of the atmosphere) and the complete set of forecasts is known as an ensemble. By using this approach the individual ensemble members can be analysed to get a better idea of which possible weather events may occur. Cannon et al [15] showed that using an ensemble of NWP forecasts of GBaggregated wind power does have an improved skill of ramp forecasting relative to climatology up to a lead time of 7 days. On smaller spatial scales, Bossavy et al [13] showed that conditioning probability forecasts by the number of NWP ensemble members forecasting a ramp can improve the reliability of the forecast for a multi megawatt wind farm in the South of France.

Here we present a case study to investigate the impact of the high frequency ramping of a cluster of offshore wind farms on the national level power system (in terms of balancing costs), if it is not forecasted by the system operator. We then explore the effectiveness of state-of-the-art high resolution NWP models of forecasting events of this nature.

To achieve the aims of this study a wide range of data have been used. The first section presents the generation characteristics of the cluster of wind farms in the Thames Estuary (currently the largest cluster of offshore wind farms in the world) for 2014 and quantifies the power ramps on time scales of less than 6 hours. The second section investigates the ramping event which occurred on $3^{\text {rd }}$ November 2014 in more detail, highlighting the impact on the national level power system using data on volume of imbalance and balancing prices. The final section investigates whether state-of-the-art high resolution forecast models are able to capture ramping events of this nature, and if so, at what forecast lead time.

This study focuses on the wind farms located in the Thames Estuary, approximately 100-200 km east of London, UK. This is the largest of the offshore clusters consisting of 5 individual farms (full details of the wind farms are given in Table 1 and Figure 1) with a total capacity of $1.7 \mathrm{GW}$, which equates to approximately $14 \%$ of the installed wind capacity in the UK. The aggregated power output from all 88 wind farms in the cluster at $5 \mathrm{~min}$ resolution for the whole of 2014 has been obtained (data coverage $>99 \%$ ). 


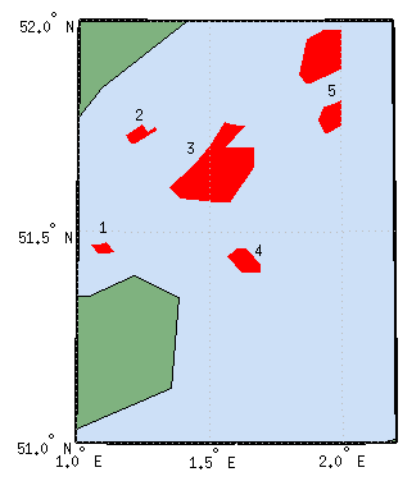

\begin{tabular}{|l|l|l|l|}
\hline & Farm & $\begin{array}{l}\text { Size } \\
(\mathbf{M W})\end{array}$ & Turbines \\
\hline 1 & Kentish Flats & 90 & Vesta V90-3MW \\
\hline 2 & Gunfleet Sands & 172 & Siemens SWT-3.6-107 \\
\hline 3 & London Array & 630 & Siemens SWT-3.6-120 \\
\hline 4 & Thanet & 300 & Vesta V90-3MW \\
\hline 5 & Greater Gabbard & 504 & Siemens SWT-3.6-107 \\
\hline
\end{tabular}

Table 1 Details of the wind farms in the Thames estuary

\section{Figure 1 Location of the wind farms in the Thames estuary}

The generation data were analysed to assess the high frequency ramping events during 2014. The definition of a wind power ramp typically refers to the change in power output over a defined time scale, usually seconds to minutes $[16,17]$ or hours $[18,19]$. In this study a ramp, $R$, is defined as the change in output of the cluster (expressed in the form of capacity factor, $\mathrm{CF}$ ) over a given time interval, $\Delta \mathrm{t}$ (as shown in equation 1$)$.

$$
\mathrm{R}=\mathrm{CF}(\mathrm{t}+\Delta \mathrm{t})-\mathrm{CF}(\mathrm{t})
$$

Figure 2 shows the magnitude of the ramps for a range of different time intervals. As shown in Drew et al [5], the distribution of the ramps for all time windows is approximately Gaussian with median values close to zero and similar frequencies of positive and negative fluctuations. As expected, the magnitude of the ramps increases with the time interval. For example, when the time window is 5 minutes $(\Delta \mathrm{t}=5$ mins), the largest fluctuation was $26.5 \%$ in comparison to $88 \%$ when the time window is 180 minutes ( $\Delta \mathrm{t}=180 \mathrm{mins}$ ). In general, the majority of the ramping events are relatively small, for the longest time window considered $(\Delta \mathrm{t}=360 \mathrm{mins}), 90 \%$ of the ramps lie within the range $-37 \%$ to $35 \%$. However, a small number of very large ramping events also occurred. For example, the maximum ramp over a time window of 60 mins was $66 \%$, this equates to a change in power output of $1.1 \mathrm{GW}$, which could make balancing the power network problematic if not well forecast.

One of the largest ramp-up events occurred on 3rd November 2014 (67\% in a period of 2 hours and 45 minutes). This was immediately followed by one of the largest ramp-down events ( $73 \%$ in a period of 1 hour and 50 minutes). This day is therefore used as a case study to consider the potential impact of high frequency local ramping events on the power system and to investigate whether high resolution meteorological forecast models can capture events of this nature.

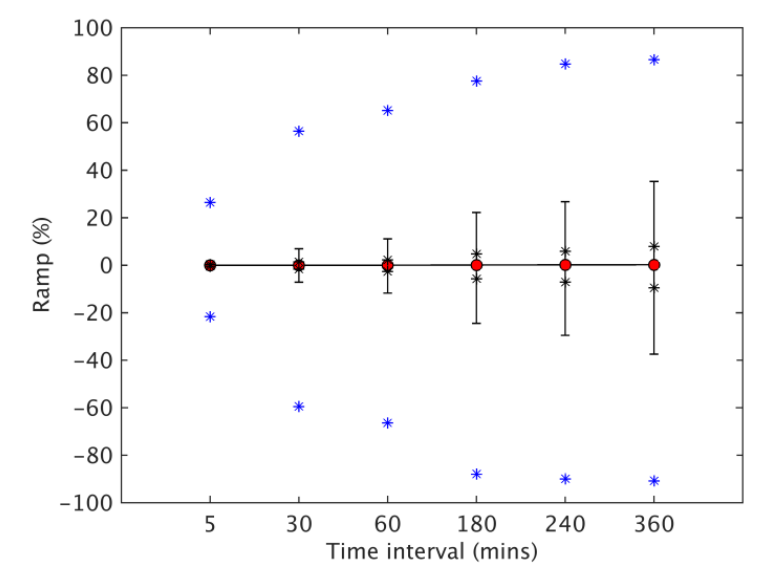

Figure 2 The magnitude of the ramps of the Thames Estuary wind farms in 2014 (expressed in the form of a change in capacity factor) for a range of time intervals. The red circles show the median, the black stars give the interquartile range, the whiskers represent the range between the $5^{\text {th }}$ and $95^{\text {th }}$ percentile and the blue stars indicate the minimum and maximum values. 
Two different high resolution models developed by the UK Met Office have been considered; (1) the deterministic UK model (UKV) which has a high resolution inner domain of $1.5 \mathrm{~km}$ (2) Met Office Global and Regional Ensemble Prediction System (MOGREPS) which produces a forecast on a resolution of approximately $2.2 \mathrm{~km}$ using 11 ensemble members and a control forecast (see Table 2 for further details). This study also considers the GB-aggregated hourly wind power forecast produced by National Grid, which is updated 4 times per day and published via the Elexon Portal [20]. This forecast was not produced using data from either of the UK Met Office models considered in this study.

\begin{tabular}{|l|l|l|}
\hline & UKV & MOGREPS UK ensemble \\
\hline Resolution & $1.5 \mathrm{~km}$ & $2.2 \mathrm{~km}$ \\
\hline Forecast length & 36 hours & 36 hours \\
\hline Run times & $0300,0900,1500,2100$ & $0300,0900,1500,2100$ \\
\hline Members & Deterministic & 12 \\
\hline
\end{tabular}

Table 2 Details of the Met Office forecast models used in this study

\subsection{Ramping case study: $3^{\text {rd }}$ November 2014}

On the morning of $3^{\text {rd }}$ November 2014 an occluded weather front moved across the South East of England which led to high wind speeds and heavy rainfall in the Thames Estuary (see figure 3). After the front moved eastwards away from the cluster of farms, their wind generation reduced dramatically, falling from $93.2 \%$ of capacity at $09: 25$ to only $8.6 \%$ at 13:00 (see Figure 4a). Following this, a trough moved across the region which corresponds with an increase in wind power generation and by 15:45 the output was back up to $76 \%$ at 15:45, however this ramp had a short duration and by 17:35 the output had reduced to only $3 \%$ (see Figure 4). The ramping event between 13:00 and 17:35 equates to an increase in power output of $1.1 \mathrm{GW}$ within 2 hours and 45 minutes, followed almost immediately by a $1.24 \mathrm{GW}$ reduction in power output within 1 hour and 50 minutes.

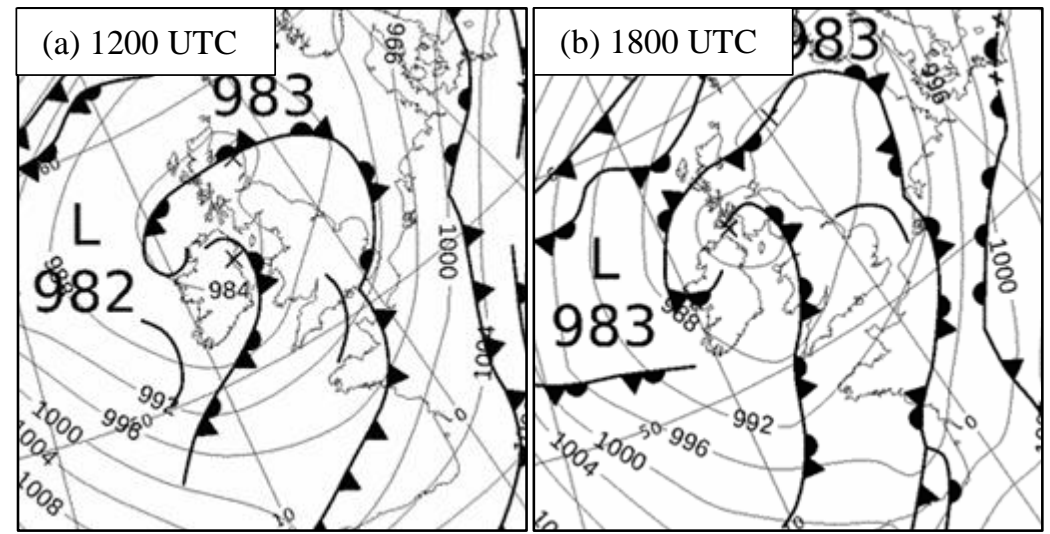

Figure 3 Met Office analysis charts for 12:00UTC (left) and 18:00UTC (right) on $3^{\text {rd }}$ November 2014

Due to large proportion of the national wind capacity located in the Thames Estuary, the ramping event is clearly observed in the GB-aggregated wind generation (Figure 4a). Between 13:40 and 15:55 wind generation increased from $1.7 \mathrm{GW}$ (capacity factor of $20 \%$ ) to $2.9 \mathrm{GW}$ (capacity factor of $35 \%$ ) before reducing down to $0.8 \mathrm{GW}$ (capacity factor of 10\%) at 17:45. This indicates that the ramping event was highly localised to the Thames Estuary and therefore related to a meteorological feature with a relatively small spatial extent. Figure 4(b) shows the National Grid forecast for 3/11/2014 for a range of lead times. In general, the forecast accurately captures the overall trend of the generation for all lead times, but the ramping event is not predicted in any of the forecasts. We speculate that this may be due to a smoothing effect caused by ensemble averaging; however full details of the forecast are not available. 

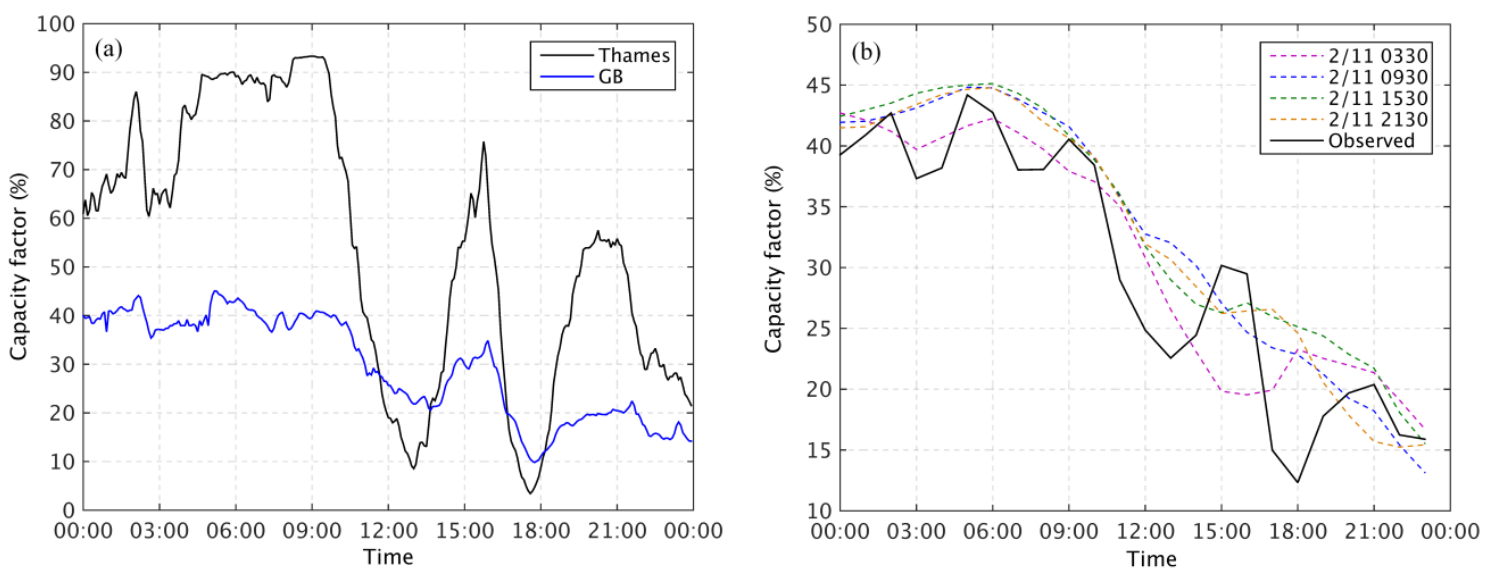

Figure 4 Wind power generation on the $3^{\text {rd }}$ November 2014. (a) 5 minute mean generation of the Thames Estuary wind farms (black) and GB-aggregated (blue) (b) The hourly GB-aggregated generation and the National Grid wind power forecasts.

\subsection{Impact on power system}

In the UK, the electricity market is based on 30 minute settlement periods. For each settlement period, suppliers and generators can contract volumes of electricity up to 1 hour prior to the delivery time (this cut-off is known as gate closure). At this point, large generating units, such as offshore wind farms must submit their expected generation, known as the final physical notification, (FPN). However, for each settlement period, a supplier might have incorrectly forecasted their demand or a supplier might not be able to generate the contracted amount and therefore there can be an imbalance between supply and demand. It is then the responsibility of the system operator (National Grid) to make the necessary actions to balance the system. This is achieved by using bids and offers in the balancing market. A bid is a proposal by a supplier to increase demand or a generator to reduce generation. An offer is a proposal by a generator to increase generation or a supplier to reduce demand.

For this case study, the final physical notifications of the wind farms in the Thames Estuary did not show the ramping event. Furthermore, it was not captured by the system operator's wind power forecast and therefore led to a large imbalance of the electricity network. As a result, National Grid was required to perform a number of actions in the balancing mechanism. The net imbalance volume (NIV) is the net of the buying and selling actions taken in the balancing mechanism. When NIV is positive it means that the system is short and therefore the system operator is accepting offers to increase generation. Conversely, when NIV is negative, the system is long and the system operator is accepting bids to reduce generation.

Figure 5 shows that in mid-afternoon (14:30 to 16:00) on 3/11/2014, the market was long, peaking at $570 \mathrm{MWh}$ at 15:30. This is a result of the unexpected pick-up in the generation in the Thames Estuary. By 17:00, the generation had drastically reduced and the market was short by $820 \mathrm{MWh}$ (the $3^{\text {rd }}$ largest negative imbalance for this time of day in 2014). This large imbalance coincided with winter darkness peak and therefore the electricity demand for this settlement period was very high, $47.6 \mathrm{GW}$ (in the top 2.5 percentile of half hourly demand in 2014). Consequently, there were fewer options, in terms of generation units, available to National Grid to balance the system. As a result, short term operating reserve (STOR) was deployed, which is expensive and therefore had implications on the system prices. 


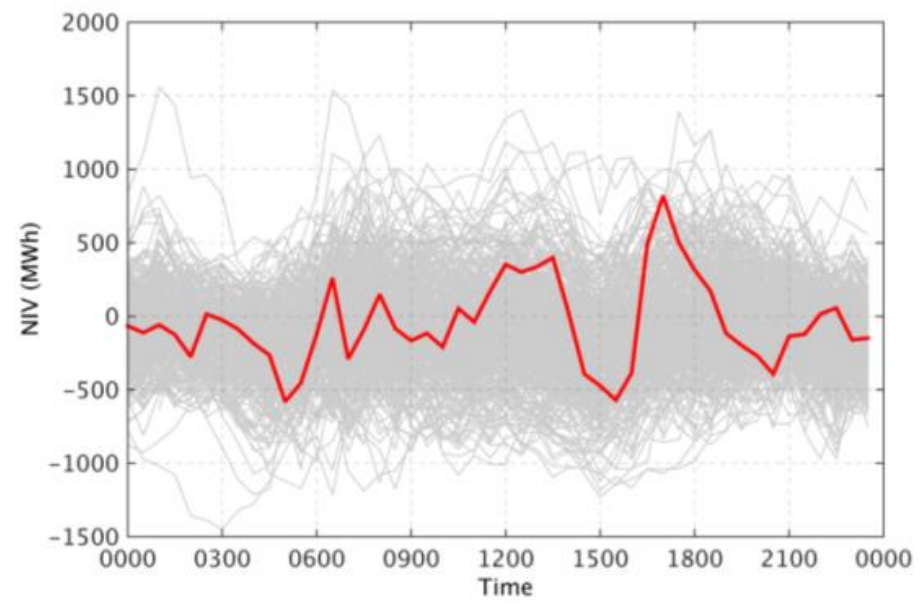

Figure 5 The net imbalance volume (NIV) of the power system for each settlement period on the $3^{\text {rd }}$ November 2014 (red). Also shown is NIV for every other day in 2014 (grey lines).

In November 2014, the costs associated with balancing mechanism bids and offers were given by the system buy price (SBP) and system sell price (SSP). The SBP is the rate paid by a party with a net deficit of imbalance energy and the SSP is the rate paid to parties with a net surplus of imbalance energy. Figure 6 shows the ramping event had a significant impact on both the SSP and SBP. At 17:00, when the system had a large deficit, the SBP increased to $£ 183$ per MWh which was the third highest price in this settlement period during the year and $16^{\text {th }}$ highest price for any settlement period in the year. SSP also increased to $£ 105$ per MWh, the $5^{\text {th }}$ highest price for that period in 2014 and $19^{\text {th }}$ highest for any settlement period during the year.
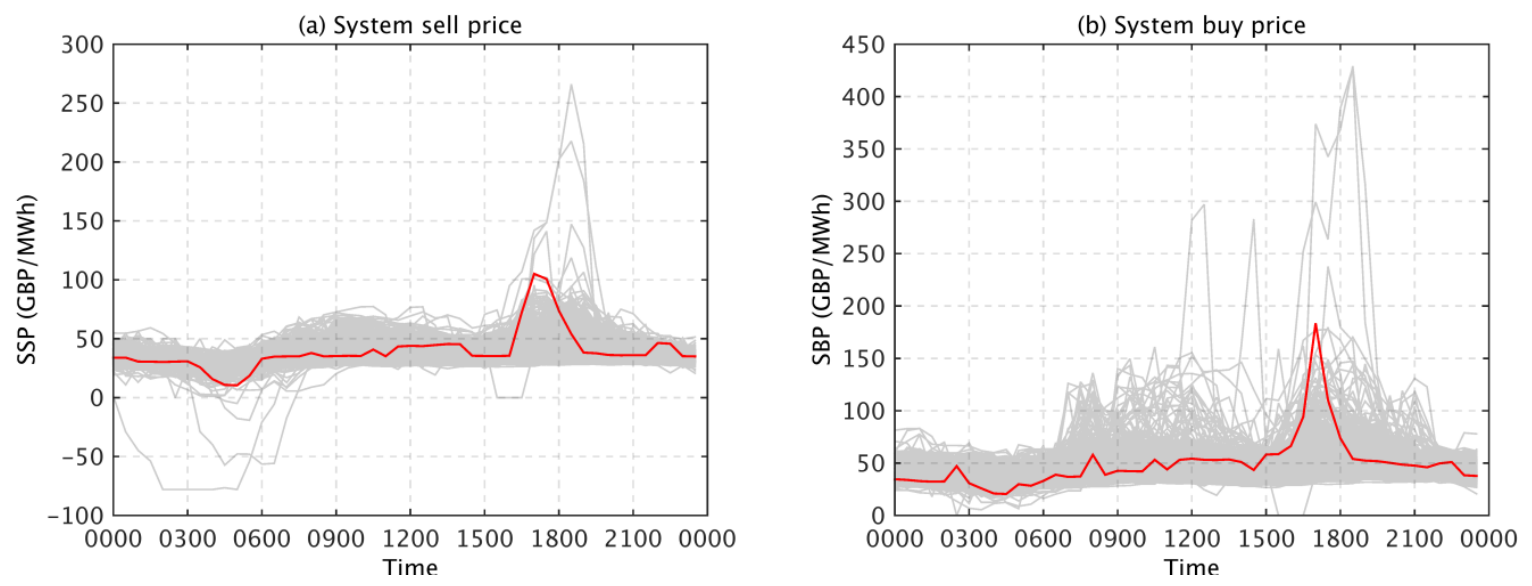

Figure 6 The system sell price (SSP) and system buy price (SBP) for each settlement period on the 3rd November 2014 (red). Also shown is the SSP and SBP for every other day in 2014 (grey lines).

\subsection{High Resolution Forecasts}

The analysis in section 3 has shown that the recent trend for clustering large amounts of capacity in a relatively small area (e.g. Thames Estuary) can lead to large local power swings, which unless accurately forecast can have a significant impact on the cost of balancing the power system. This effect is likely to be exacerbated following the construction of the wind farms proposed as part of the next phase of offshore wind development in the UK. The aim of this section is to investigate whether state-of-the-art high resolution meteorological forecast models capture local ramping events, using the ramp on 3/11/2016 as a case study. 


\subsection{Meteorological conditions}

The output from the high resolution models has been assessed to determine the meteorological conditions on $3^{\text {rd }}$ November 2014. Figure 7 shows the rainfall and wind from 12:00 and 15:00 UTC derived by a single ensemble member of the MOGREPS forecast initialised at 09:00 UTC. The figures clearly show the elevated wind speeds and heavy rainfall in the English Channel associated with the main front which passed over the region earlier in the day. There is also a feature behind the front with large amounts of rainfall which propagates from south west to north east along the front. This is related to the trough marked on the analysis chart at 12 and 18 UTC (see Figure 3). The winds associated with this feature are relatively low over land but pick up as it passes over the Thames Estuary at 14:00 UTC.

Complete analysis of the dynamics of this feature is beyond the scope of this paper; however there are several things of importance to consider. Firstly, the acceleration of the winds as the rainfall feature passes from the land into the Thames estuary, which is possibly due to change in the surface roughness. The most important thing to note is the way that the frontal region is comprised of small scale banded structures with can lead to large local fluctuations in wind speed. The magnitude of the uncertainty in the location and detailed structure of such banded features is larger than their spatial scale meaning that ensemble mean forecasts will fail to capture them (this is explored detail in section 4.3).
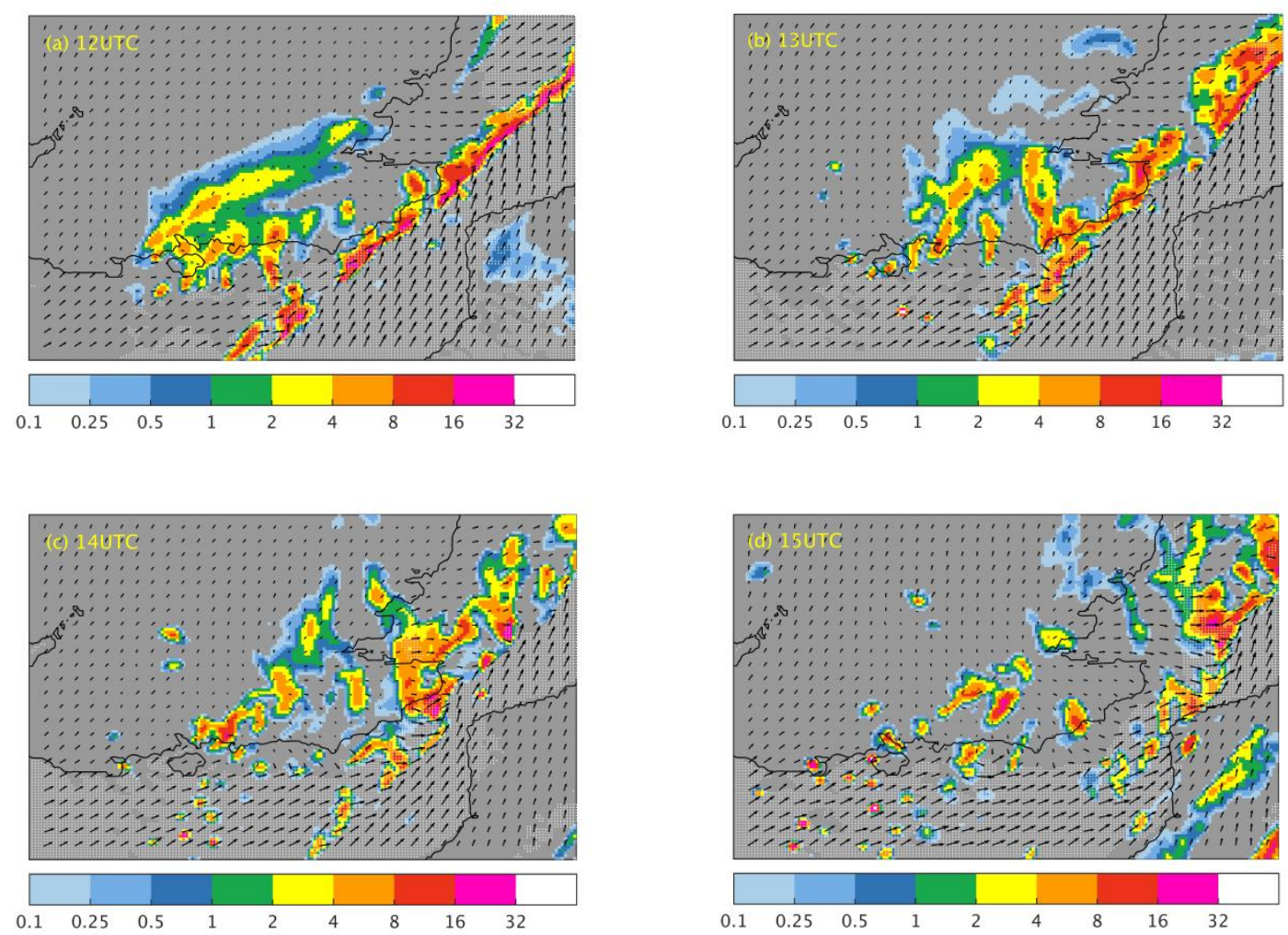

Figure 7 Instantaneous wind and Rainfall rate $\left(\mathrm{mm} \mathrm{hr}^{-1}\right)$ from 12:00-16:00 UTC on $3^{\text {rd }}$ November 2014 derived by MOGREPS (ensemble member 4 from forecast initialised at 09:00 on $3^{\text {rd }}$ November 2014). The white stippling shows wind speeds at $10 \mathrm{~m}$ in excess of $10 \mathrm{~ms}^{-1}$.

\subsection{Deterministic Model (UKV) Results}

The model forecasts have been obtained for a range of initialisation times (6 hourly intervals from 03:00 on 02/11/2014 to 09:00 on 03/11/2014). The generation of the cluster has been estimated by applying the power curve produced by the turbine manufacturer to the model derived wind data defined in two ways: (1) turbine location method: the wind speed from the model at the exact location 
of each of the turbines (2) area maximum wind speed method: the maximum wind speed within a 10 $\mathrm{km}$ radius of each of the turbines. Figure 8a shows that using the wind speed at the exact location of the turbines ('point') produces an underestimate of the ramp in generation. Between 15:00 and 16:00 the capacity factor of the region increases by $19 \%$, before reducing by $17 \%$ by $18: 00$ this equates to a magnitude error of $30 \%$. However, using the maximum wind speed within a $10 \mathrm{~km}$ area of each of the turbines produces a clear, large mid-afternoon ramp up of $44 \%$ between 15:00 and 17:00 followed by a ramp down of $40 \%$. This reduces the magnitude error to only $8 \%$, but there is still a 2 hour phase error in the forecast. This indicates that while the model was able to produce the band of post-frontal high wind speeds, it did not have the timing and position of the feature exactly correct.

By using the area maximum wind speed method to determine wind farm power output, there is an indication of a large ramp present in the forecast from the UKV 1.5 model out to a lead time of 24 hours. Figure $8 \mathrm{~b}$ shows that the forecast initialised at $15: 00$ on $02 / 11 / 2014$ produces a ramp of $41 \%$ (magnitude error of $8 \%$ ), however the ramp peaks at 1300UTC therefore there is a 2 hour phase error. As the forecast lead time decreases the representation of the ramp improves and by 03:00 on 3/11/14, the magnitude error is reduced to $5 \%$ but the phase error remains at 2 hours.
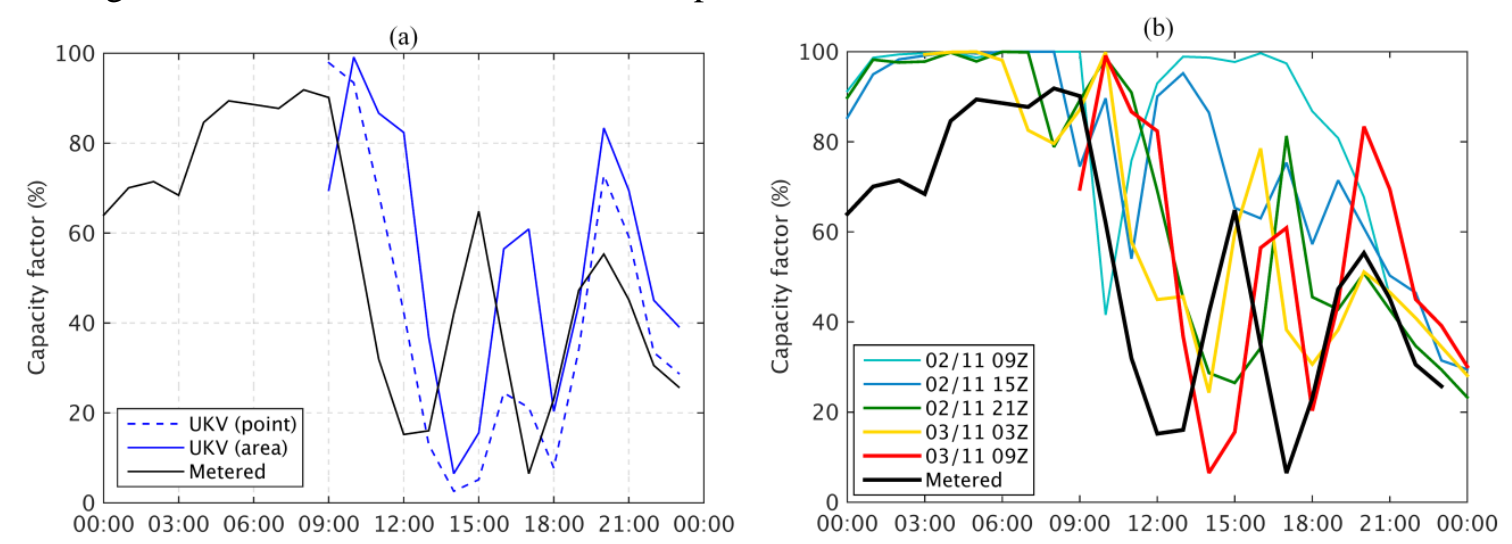

Figure 8 The hourly generation of the wind farms in the Thames Estuary compared to power forecast derived from the Met Office UKV1.5 model. (a) Comparison with power derived from the UKV wind speed (forecast initialised at 03/11/2014 at 09:00) at the precise location of each turbine (point) and with the maximum wind speed within $10 \mathrm{~km}$ of each turbine (area). (b) Comparison with the wind power forecast for a range of lead times.

\subsection{Ensemble Model (MOGREPS) Results}

For all forecast lead times, there is a large spread in the capacity factor across the 12 different ensemble members on the afternoon of 3/11/2014 (see Figure 9). It is clear from the figures that the ensemble mean grossly underestimates the variability in generation. This is due to the smoothing that occurs when averaging over the ensemble members and highlights the importance of considering the trajectory of individual ensemble members when estimating ramp events. An assessment of the forecast of the different ensemble members has been made focussing on the period from 12:00 to 18:00 on 3/11/2014. To prevent large differences between successive forecasts, the forecasts from consecutive initialisation times are typically combined to produce a 24 member ensemble. For the forecast initialised at 09:00 and 15:00 on 02/11/2014 (27-21 hours prior to the ramp), the majority of the members have relatively high generation during the period; however $21 \%$ of members show a ramp with a magnitude of at least $20 \%$. As the forecast lead time decreases the number of members predicting a ramp $(\mathrm{R}>20 \%)$ increases (see Table 3). For the forecast based on initialisation times of 03:00 and 09:00 UTC on 3/11/2014, there is a 75\% probability of a ramp occurring (18 members forecast a ramp). Table 3 also shows that some ensemble members do predict a very large ramping event $(\mathrm{R}>40 \%)$ during the 3 hours either side of when the event occurred. For example, for the forecast at $12: 00$ on $02 / 11 / 2014$ there is a $16.7 \%$ probability of a large ramp 
( $\mathrm{R}>40 \%$ ) occurring in this period. This increases to $33.3 \%$ for the forecast at $06: 00$ on $03 / 11 / 2014$. However, the probabilities are significantly reduced when the time window is restricted to 1 hour either side of the event- indicating a phase error in the forecast.

For each ensemble member with a predicted ramp in the time window 12:00-18:00, the magnitude and phase error has been determined. In general, the magnitude of the ramps predicted by the individual ensemble members becomes more accurate as the lead time decreases. Figure 10 shows that the latest forecast (initialised at 09:00 on 3/11/2014) has 7 out of 12 members predicting a ramping event, with a range of magnitudes from $17-70 \%$, but for two members the magnitude error is less than $5 \%$. Figure 10 also shows that the magnitude error of the ramps predicted by the UKV1.5 model is relatively low (less than 8\%) for all lead times, this is lower than all but one ensemble member for the corresponding MOGREPS forecast. However, there is a consistent 2 hour phase error for all of the UKV forecasts.

\begin{tabular}{|l|c|c|c|c|}
\hline Forecast & $\mathrm{P}(\mathrm{R}>20 \%, \mathrm{t} \pm 3)$ & $\mathrm{P}(\mathrm{R}>20 \%, \mathrm{t} \pm 1)$ & $\mathrm{P}(\mathrm{R}>40 \%, \mathrm{t} \pm 3)$ & $\mathrm{P}(\mathrm{R}>40 \%, \mathrm{t} \pm 1)$ \\
\hline 02/11/2014 12:00 & 20.8 & 20.8 & 4.2 & 4.2 \\
\hline 02/11/2014 18:00 & 25.0 & 16.7 & 12.5 & 4.2 \\
\hline 03/11/2014 00:00 & 45.8 & 20.8 & 20.8 & 4.2 \\
\hline 03/11/2014 06:00 & 62.5 & 29.2 & 33.3 & 12.5 \\
\hline
\end{tabular}
of the observed ramping event based on the MOGREPS forecast.

\section{1}

292

\subsection{Discussion}

Analysis of the meteorological conditions on $3^{\text {rd }}$ November 2014 has shown that the ramping event was caused by a trough which formed behind a large weather front. The trough was a relatively small feature (spatial extent of approximately 100-150 km) and therefore the ramping was localised to the wind farms in the Thames Estuary. The size of the feature presents a series of challenges to forecasting ramping events of this nature. Firstly, uncertainty in its location can have a significant impact on the predicted wind generation. For example, the high resolution deterministic forecast predicted the presence of the trough at a lead time of 24 hours, however as the feature is not predicted in exactly the right location there is a large error in the predicted wind power of the cluster. This error can be reduced by estimating the power output using the maximum wind speed within a given area of the turbines rather than the wind speed at the exact location of each turbine. Secondly, the size of the feature also means that it is unlikely to be captured in a wind power forecast which uses the ensemble mean. As shown in section 4.3, individual ensemble members capture the feature but in slightly different locations, so the mean smears out the increased generation.

Despite the relatively small size of the feature, the high resolution deterministic model was able to forecast the ramping event at a lead time of 24 hours but with a phase error of -2 hours and a magnitude error of $-8 \%$. When the lead time reduced to 12 hours, the magnitude of the ramp was accurately forecast to within $5 \%$ but the phase error remained at 2 hours (but opposite sign). In addition, a number of ensemble members also predicted a ramp up to 36 hours in advance. For lead times from 36 down to 6 hours there was a large spread in the ensemble members for the period during which the ramping occurred, indicating large uncertainty in the predicted wind generation. Access to such forecasts would have allowed National Grid to have prepared for the ramping event in advance, reducing the number of transactions required in the balancing mechanism and ultimately the cost of electricity. 
While the NWP models were shown to be of benefit for this particular, high-impact case study, further work is required to place the performance of the models in to context. The skill of the models at predicting local ramping events could be determined over a long time period (large number of ramping events) and compared to that of a low resolution global NWP model. This would quantify the benefit of high resolution models and determine the bounds of predictability of local ramping events.

(a) $02 / 1109 Z$

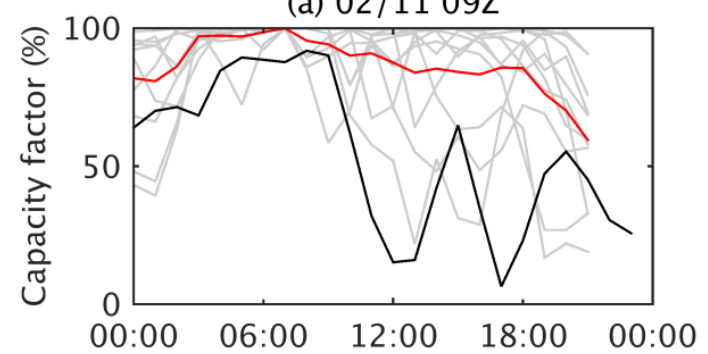

(c) $02 / 1121 Z$

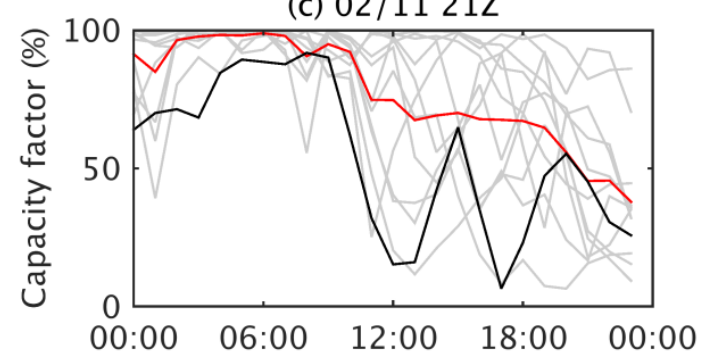

(e) $03 / 1109 Z$

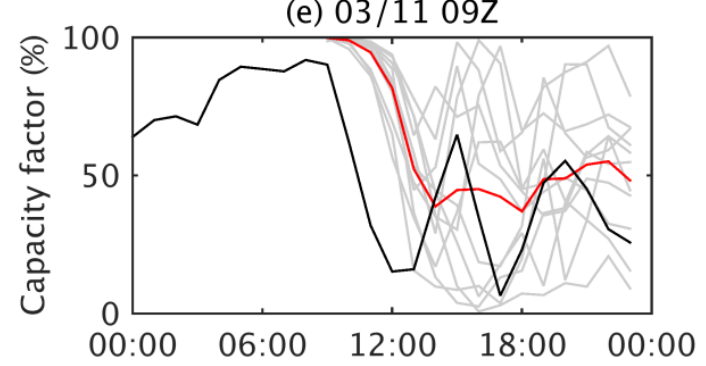

(b) $02 / 1115 Z$

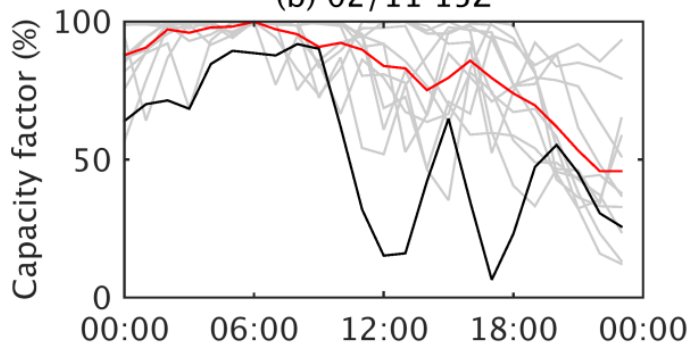

(d) $03 / 1103 Z$

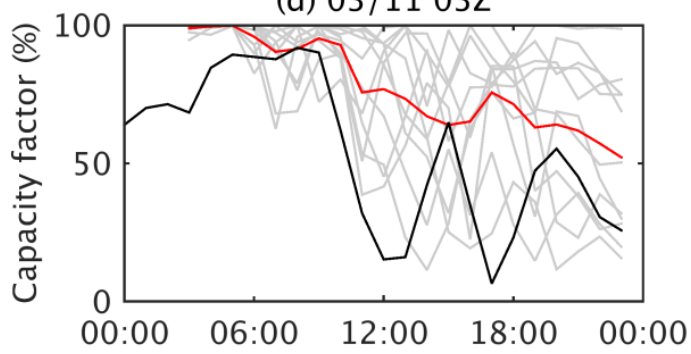

Figure 9 The wind power forecast for the Thames Estuary wind farms derived from the MOGREPS model output for a range of forecast lead times. The figure shows the forecast derived from each ensemble member (grey lines) as well as the ensemble mean (red lines) and is compared to the measured hourly output (black). 


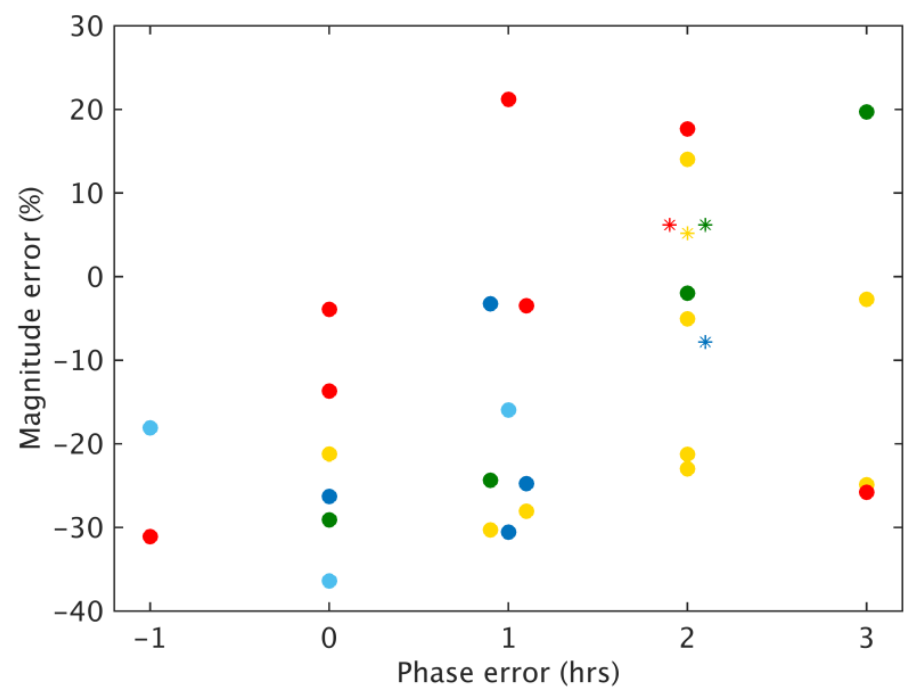

Figure 10 The magnitude error (expressed in the form of capacity factor) and phase error of the ramps predicted by the individual MOGREPS ensemble members (circles) and the UKV1.5 forecast (stars). Data is shown for the range of lead times. 02/11 at 09:00Z (light blue), 02/11 at 15:00Z (dark blue), 02/11 at 21:00Z (green), 03/11 at 03:00Z (yellow) and 03/11 at 09:00Z (red).

\subsection{Conclusions}

In recent years there has been a significant change in the distribution of wind farms in Great Britain, with a trend towards very large offshore wind farms clustered together in several zones. This study has shown these clusters can experience large ramping events on time scales of less than 6 hours as the impact of local meteorological phenomena on the power production is strong. For example, for the wind farms in the Thames Estuary, 10\% of the ramps over a 6 hour time window were in excess of $30 \%$ of the total capacity. Due to the large capacity of the farms, these wind power fluctuations can present challenges for the system operator in maintaining the balance between supply and demand on a national scale.

A case study of the wind farms in the Thames Estuary has shown the implications of an unpredicted local ramping event on the cost of balancing the power system. On $3^{\text {rd }}$ November 2014, there was an increase in power output of $1.1 \mathrm{GW}$ within 2 hours and 45 minutes, followed almost immediately by a $1.2 \mathrm{GW}$ reduction in output within 1 hour and 50 minutes. As this event was not captured by the forecast used by the system operator the market was long by 570 MWh at 15:30 (due to the unexpected pick-up in the generation in the Thames Estuary) and then short by 820 MWh at 17:00 as the generation had drastically reduced. The large imbalance coincided with a period of very high demand and therefore there were fewer generation units available to help the system operator to balance the system. Consequently, expensive short term operating reserve was deployed which led to a spike in the system buy price of 183 per MWh which was the $16^{\text {th }}$ highest price during the year.

The construction of even larger offshore wind zones, outlined in Round 3 of the UK's offshore wind development would exacerbate this problem. Furthermore, a number of other nations are seeking to dramatically increase their own offshore wind capacity. Consequently, there is a need for accurate regional wind power forecasts to minimise the costs of managing the system. In recent years a number of state-of-the-art high resolution forecast models have been developed. For this case study, these models were able to capture the meteorological feature which caused the localised ramping at a lead time of up to 24 hours and therefore the use of these forecasts would have been of benefit to the system operator. As system operators continue to seek to improve their forecasting of weather dependent renewable generation, the new forecast models should be considered. However, further 
work is required to determine how well the model captures the high frequency ramping for a larger number of events.

This study has also shown that careful interpretation of the forecast is required. For example, due to possible errors in the position of small scale meteorological features in the models, a wind power forecast derived from the predicted wind speeds at the exact location of each turbine can contain large errors. It is therefore recommended that wind power estimates are based on the maximum wind speed within a given area of the turbines. In addition, the ensemble mean power forecast is not suitable when considering ramping events due to the smoothing that occurs when averaging over the ensemble members. This highlights the importance of considering the trajectory of individual ensemble members when estimating ramp events as well as the information about forecast uncertainty that they provide.

\section{Acknowledgements}

This work was funded by National Grid via the Network Innovation Allowance (NIA_NGET0128). The authors would particularly like to thank David Lenaghan (National Grid) for helpful advice throughout this project and the aggregated wind farm generation data used in this paper. We would also like to thank the Met Office for allowing access to forecast output from MOGREPS-UK. We acknowledge use of the MONSooN system, a collaborative facility supplied under the Joint Weather and Climate Research Programme, a strategic partnership between the UK Met Office and the Natural Environment Research Council

\section{References}

1. Department of Energy and Climate Change. Digest of United Kingdom Energy Statistics 2015; https://www.gov.uk/government/collections/digest-of-uk-energy-statistics-dukes, 2015

2. The Crown Estate. Offshore wind operational report: January-December 2015; http://www.thecrownestate.co.uk/energy-minerals-and-infrastructure/offshore-wind-energy/ 2016

3. National Grid. UK Future energy scenarios. Retrieved from http://www2.nationalgrid.com/mediacentral/uk-press-releases/2013/national-grid-s-uk-futureenergy-scenarios-2013/ 2013.

4. Drew, D., Cannon, D., Brayshaw, D., Barlow, J., \& Coker, P. (2015). The Impact of Future Offshore Wind Farms on Wind Power Generation in Great Britain. Resources, 4(1), 155-171. doi:10.3390/resources4010155

5. Drew, D., Cannon, D., Barlow, J., \& Coker, P. (2015). Quantifying the high frequency variability in regionally aggregated wind power generation, submitted to Resources Journal

6. Vincent, C. L., Pinson, P., \& Giebel, G. (2010). Wind fluctuations over the North Sea. International Journal of Climatology, 1595(June 2010), n/a-n/a. doi:10.1002/joc.2175

7. Trombe, P., Pinson, P., Vincent, C., Bøvith, T., Cutululis, N. A., Draxl, C., Giebel, G., et al. (2013). Weather radars - the new eyes for offshore wind farms? Wind Energy, vol 17, no. 11, pp. 1767-1787, doi:10.1002/we

8. Potter, C. W., Grimit, E., \& Nijssen, B. (2009). Rapid Ramp Event Forecast Tool. IEEE Power systems Conference (pp. 1-5). Seattle, Washington.

9. Soman, S. S., Zareipour, H., Member, S., Malik, O., \& Fellow, L. (2010). A Review of Wind Power and Wind Speed Forecasting Methods With Different Time Horizons. North American Power Synposium (pp. 1-8). Arlington, Texas. 
10. Giebel, G., Kariniotakis, G., \& Brownsword, R. (2003). The State-Of-The-Art in Short-Term Prediction of Wind Power A Literature Overview (pp. 1-36). Project Anemos

11. Sweeney, C. P., Lynch, P., \& Nolan, P. (2013). Reducing errors of wind speed forecasts by an optimal combination of post-processing methods. Meteorological Applications, 20(1), 32-40. doi:10.1002/met.294

12. Cutler, N., Kay, M., Jacka, K., \& Nielsen, T. S. (2007). Detecting, Categorizing and Forecasting Large Ramps in Wind Farm Power Output Using Meteorological Observations and WPPT. Wind Energy, (July), 453-470. doi:10.1002/we.235

13. Bossavy, A., Girard, R., \& Kariniotakis, G. (2013). Forecasting ramps of wind power production with numerical weather prediction ensembles. Wind Energy, (February 2012), 5163. doi:10.1002/we

14. Haupt, S. E., \& Thompson, G. (2011). A Wind Power Forecasting System to Optimize Power Integration. ES1002: Workshop March 22nd-23rd 2011.

15. Cannon, D. J., Brayshaw, D. J., Methven, J. and Drew, D. (2016). Determining the bounds of skilful forecast range for probabilistic prediction of system-wide wind power generation. Met. Zeitschrift, doi:10.1127/metz/2016/0751

16. Sorensen, P., Cutululis, N. A., Vigueras-Rodríguez, A., Madsen, H., Pinson, P., Jensen, L. E., Hjerrild, J., et al. (2008). Modelling of Power Fluctuations from Large Offshore Wind Farms. Wind Energy, 11(October 2007), 29-43. doi:10.1002/we.246

17. Sørensen, P., Hansen, A. D., \& Rosas, P. A. C. (2002). Wind models for simulation of power fluctuations from wind farms. Journal of Wind Engineering and Industrial Aerodynamics, 90(12-15), 1381-1402. doi:10.1016/S0167-6105(02)00260

18. Ferreira, C., Gama, J., Matias, L., Botterud, A., and Wang, J. (2010). A survey of wind power ramp forecasting. US Department of Energy, Office of Energy Efficiency and Renewable Energy, Wind and Water Program.

19. Cannon, D. J., Brayshaw, D. J., Methven, J., Coker, P. J., \& Lenaghan, D. (2015). Using reanalysis data to quantify extreme wind power generation statistics: A 33 year case study in Great Britain. Renewable Energy, 75, 767-778. doi:10.1016/j.renene.2014.10.024

20. Elexon Portal (2016) Balancing Mechanism Reporting Service, available at: https://www.elexonportal.co.uk/news/latest?cachebust=7ght2ay92n 